\title{
Determinants of adherence to physical cancer rehabilitation guidelines among cancer patients and cancer centers: a cross-sectional observational study
}

\author{
Charlotte IJsbrandy ${ }^{1,2,3}$ (D) Petronella B. Ottevanger ${ }^{2}$ - Winald R. Gerritsen ${ }^{2}$ - Wim H. van Harten ${ }^{4,5}$. \\ Rosella P. M. G. Hermens ${ }^{1}$
}

Received: 30 December 2019 / Accepted: 25 July 2020 / Published online: 28 September 2020

(C) The Author(s) 2020

\begin{abstract}
Purpose To tailor implementation strategies that maximize adherence to physical cancer rehabilitation (PCR) guidelines, greater knowledge concerning determinants of adherence to those guidelines is needed. To this end, we assessed the determinants of adherence to PCR guidelines in the patient and cancer center.

Methods We investigated adherence variation of PCR guideline-based indicators regarding [1] screening with the Distress Thermometer (DT), [2] information provision concerning physical activity (PA) and physical cancer rehabilitation programs (PCRPs), [3] advice to take part in PA and PCRPs, [4] referral to PCRPs, [5] participation in PCRPs, and [6] PA uptake (PAU) in nine cancer centers. Furthermore, we assessed patient and cancer center characteristics as possible determinants of adherence. Regression analyses were used to determine associations between guideline adherence and patient and cancer center characteristics. In these analyses, we assumed the patient (level 1) nested within the cancer center (level 2).

Results Nine hundred and ninety-nine patients diagnosed with cancer between January 2014 and June 2015 were included. Of the 999 patients included in the study, 468 (47\%) received screening with the DT and 427 (44\%) received information provision concerning PA and PCRPs. Subsequently, 550 (56\%) patients were advised to take part in PA and PCRPs, which resulted in 174 (18\%) official referrals. Ultimately, 280 (29\%) patients participated in PCRPs, and 446 (45\%) started PAU. Screening with the DT was significantly associated with information provision concerning PA and PCRPs (OR 1.99, 95\% CI 1.47-2.71), advice to take part in PA and PCRPs (OR 1.79, 95\% CI 1.31-2.45), referral to PCRPs (OR 1.81, 95\% CI 1.18-2.78), participation in PCRPs (OR 2.04, 95\% CI 1.43-2.91), and PAU (OR 1.69, 95\% CI 1.25-2.29). Younger age, male gender, breast cancer as the tumor type, $\geq 2$ cancer treatments, post-cancer treatment weight gain/loss, employment, and fatigue were determinants of guideline adherence. Less variation in scores of the indicators between the different cancer centers was found. This variation between centers was too low to detect any association between center characteristics with the indicators.
\end{abstract}

Electronic supplementary material The online version of this article (https://doi.org/10.1007/s11764-020-00921-8) contains supplementary material, which is available to authorized users.

Charlotte IJsbrandy

Charlotte.IJsbrandy@Radboudumc.nl

Petronella B. Ottevanger

Nelleke.Ottevanger@Radboudumc.nl

Winald R. Gerritsen

Winald.Gerritsen@Radboudumc.nl

Wim H. van Harten

W.v.Harten@NKI.nl

Rosella P. M. G. Hermens

Rosella.Hermens@Radboudumc.nl
1 Scientific Institute for Quality of Healthcare (IQ Healthcare), Radboud Institute for Health Science (RIHS), Radboud University Medical Center Nijmegen, PO Box 9101, Nijmegen 6500, HB, The Netherlands

2 Department of Medical Oncology, Radboud Institute for Health Science (RIHS), Radboud University Medical Center Nijmegen, Nijmegen, The Netherlands

3 Department of Radiation Oncology, Radboud Institute for Health Science (RIHS), Radboud University Medical Center, Nijmegen, The Netherlands

4 Division of Psychosocial Research and Epidemiology, Netherlands Cancer Institute, Amsterdam, The Netherlands

5 Department of Health Technology and Services Research, MB-HTSR, University of Twente, Enschede, The Netherlands 
Conclusions The implementation of PCR guidelines is in need of improvement. We found determinants at the patient level associated with guideline-based PCR care.

Implications for Cancer Survivors Implementation strategies that deal with the determinants of adherence to PCR guidelines might improve the implementation of PCR guidelines and the quality of life of cancer survivors.

Keywords Exercise $\cdot$ Health plan implementation $\cdot$ Guidelines $\cdot$ Neoplasm $\cdot$ Rehabilitation $\cdot$ Survivors

$\begin{array}{ll}\begin{array}{l}\text { Abbreviations } \\ \text { EORTC }\end{array} & \begin{array}{l}\text { The European Organization for Research } \\ \text { aLQ-C30 }\end{array} \\ \text { Qnd Treatment of Cancer Quality of Life } \\ \text { Questionnaire } \\ \text { Intra-class coefficient } \\ \text { MFI-20 } & \text { Multidimensional Fatigue Inventory-20 } \\ \text { OR } & \text { Odds ratio } \\ \text { PA } & \text { Physical activity } \\ \text { PAM-13 } & \text { Patient Activity Measurement-13 } \\ \text { PAU } & \text { Physical activity uptake } \\ \text { PCR } & \text { Physical cancer rehabilitation } \\ \text { PCR guideline } & \begin{array}{l}\text { Physical cancer rehabilitation guideline } \\ \text { PCRP }\end{array} \\ \text { QoL } & \text { Physical cancer rehabilitation program } \\ & \text { Quality of life }\end{array}$

\section{Introduction}

It is well known that the physical activity (PA) levels of patients affected by cancer generally decline [1], and only a small proportion of the patients with cancer get sufficient PA during treatment $[2,3]$. The majority of patients fail to return to pre-diagnosis activity levels following treatment $[2$, 3]; however, PA improves both the physical and psychosocial functioning [4-15] of patients affected by cancer by decreasing fatigue $[5,7,8,16-25]$, improving cardiopulmonary fitness $[7,8,16,26]$, and improving quality of life $(\mathrm{QoL})[8,16$, 19, 21, 26-32] while also decreasing cancer recurrence and cancer-specific mortality [33-36].

Evidence-based guidelines recommend the implementation of physical cancer rehabilitation programs (PCRPs) or other initiatives to improve the uptake of PA during and after cancer treatment $[16,35-43]$. As the number of cancer survivors is still rising, the implementation of these guidelines has become an increasingly important topic worldwide [43, 44]. Depending on the cancer site and treatment, $30-90 \%$ of cancer patients require physical rehabilitation [45-48]. Regrettably, it appears that adherence to current guidelines on physical cancer rehabilitation (PCR) is low [49-53], and material on approaches to implementing PCR guidelines is scarce [54-58]. Patients who will accept and benefit from PCRPs can be identified by means of the Distress Thermometer (DT) $[59,60]$. Using the DT for screening appears to be a good starting point for accomplishing adherence to current PCR guidelines, but evidence supporting this hypothesis is missing.
Most guidelines do not implement themselves and require implementation strategies [61, 62]. Various strategies have been advocated for the implementation of healthcare innovations, each based on different assumptions and theories on human behavior and organizations [61, 63-70]. Strategies tailored to determinants and barriers are recommended $[71,72]$ because tailoring is expected to contribute to their effectiveness [73] (odds ratios of 1.27 to 1.93 [74]). To design tailored implementation strategies, we used the stepwise theoretical framework of Grol and Wensing's "Implementation of Change Model" [75, 76]. In doing so, we gained insight into current practice, potential determinants that predict adherence, and possible barriers and facilitators [77, 78] influencing PCR guideline implementation. Determinants and barriers often arise at multiple levels within the healthcare system (at the patient, healthcare provider (HCP), cancer center, and healthcare organization levels) [79]. To assess the barriers, we performed two earlier studies $[77,78]$. We found multiple barriers at the level of PCR guidelines, PCRPs, and patients, but also at the level of HCPs, healthcare organization, and governance. Since a strategy that is additionally tailored to determinants of implementation is more effective, we also wanted to investigate determinants of PCR guideline implementation [73].

Research in other fields of care has demonstrated that a variety of determinants of the targeted patients and cancer centers can explain poor implementation of the recommended care [80-85]. Tailoring the strategy to these determinants will improve the chance to successful guideline implementation. Assessing determinants before starting the implementation is comparable with clinical practice in which a diagnosis is made so that the right treatment can be chosen [86]. However, determinants related to PCR guidelines being followed are currently not well known. To help tailor implementation strategies and maximize guideline adherence, and thereby the number of patients participating in PCRPs, more knowledge about the determinants of adherence to PCR guidelines is needed.

We aimed to (1) assess the adherence to PCR guidelines for patients with cancer. We hypothesized that the use of the distress thermometer (DT) could help to identify patients in need of PCRPs and persuade them to benefit from them; therefore, we also aimed to (2) assess the effect of the use of the DT on this adherence. Furthermore, we aimed to (3) analyze the determinants of adherence to PCR guidelines of (3a) cancer 
centers and ( $3 b)$ the patients with cancer treated in these cancer centers.

\section{Methods}

\section{Study design}

An observational study was conducted to assess adherence to and determinants of PCR guidelines in nine cancer centers. This was done at cancer centers and on patients who have been treated in these cancer centers, while taking the clustering of data into account. The existing registration systems and patient and HCP questionnaires were utilized.

\section{Study population and recruitment}

The patient cohort was recruited from the nine participating cancer centers located in categorical, university, teaching, and non-teaching hospitals in the Netherlands. The cancer registry was used for the selection of eligible patients: all patients with a history of breast, female organ, urogenital organ, gastrointestinal, and hematological malignancies diagnosed between January 2014 and June 2015 who had successfully completed their primary treatment without signs of recurrence or metastases. The treating physicians asked them whether they wanted to participate and give informed consent. One HCP at each center was asked to collect data on the characteristics of their cancer center.

\section{Data collection}

Indicator scores for processes and patient outcomes of care as well as patient and center characteristics were measured to assess adherence to PCR guidelines and the determinants of guideline adherence. The indicators were based on (inter)national, evidence-based PCR guidelines [37, 87, 88]. A national panel of 10-12 professional experts and patients used the RAND-modified Delphi method to develop the indicators $[89,90]$. We developed indicators that measure PCR guideline adherence that have the potential to be valuable, reliable, measurable, applicable, have improvement potential, have preferably minimum amount of missing data, and contain discriminatory capacity. The main indicator was distress screening with the DT $[91,92]$. The other indicators were (1) information provision concerning PA and PCRPs, (2) advice to take part in PA and PCRPs, (3) referral to PCRPs, (4) participation in PCRPs, and (5) PA uptake (PAU). In supplement 1, the definitions of the psychometric characteristics used to develop and measure the quality of the indicators used is comprehensively explicated. All developed indicators showed to be valuable, reliable, measurable, applicable, have improvement potential, have minimum amount of missing data, and four indicators contain sufficient discriminatory capacity. Supplement 2 provides an overview of the range of potential values of each developed and measured indicator regarding the psychometric characteristics.

The indicators and patient characteristics were measured among patients by means of questionnaires. To assess cancer center characteristics, existing registry systems and questionnaires distributed among HCPs involved in cancer care in the nine cancer centers were used.

\section{Operational definition of the main indicator}

Screening with the DT The percentage is calculated by the number of patients included in the study who indicated in the patients' questionnaire having received screening with the DT $[91,92]$ one or more times during their cancer treatment or follow-up visits from one or more healthcare professionals from the cancer center where they were treated for cancer, divided by the total number of patients included in the study who completed the patients' questionnaire.

The questionnaire asked patients if they had received screening with the DT $[91,92]$. A photograph of the DT was shown in the questionnaire.

Supplement 3 provides a detailed description of the DT and the other questionnaires used in the present study.

\section{Operational definition of the other indicators}

Information provision concerning PA and PCRPs The percentage is calculated by the number of patients who indicated in the patients' questionnaire that they received information about PA and PCRPs from one or more healthcare professionals from the cancer center where they were treated for cancer one or more times during their cancer treatment or follow-up visits, divided by the total number of patients included in the study who completed the patients' questionnaire.

Advice to take part in PA and PCRPs The percentage is calculated by the number of patients who indicated in the patients' questionnaire that they received advice to improve their PA and join a PCRP during and after cancer treatment from one or more healthcare professionals from the cancer center where they were treated for cancer one or more times during their cancer treatment or follow-up visits, divided by the total number of patients included in the study who completed the patients' questionnaire.

Referral to PCRPs The percentage is calculated by the number of patients who indicated in a patients' questionnaire that they received a referral to a PCRP by one of their healthcare professionals from the cancer center where they were treated for the cancer one or more times during their cancer treatment or 
follow-up visits, divided by the total number of patients included in the study who completed the patients' questionnaire.

Participation in PCRPs The percentage is calculated by the number of patients who indicated in a patients' questionnaire that they had joined a PCRP during and/or after their cancer treatment, divided by the total number of patients included in the study who completed the patients' questionnaire.

PA uptake (PAU) The percentage is calculated by the number of patients who indicated in a patients' questionnaire that their PA had increased following cancer and cancer treatment compared with PA prior to cancer treatment, divided by the total number of patients included in the study who completed the patients' questionnaire.

\section{Characteristics of patients and cancer centers}

Patient characteristics The patient characteristics were age (continuous), gender (male or female), nationality (Dutch or other nationality), tumor type (breast, female organ, urogenital organ, and gastrointestinal and hematological malignancies), type of any treatment previously received for treating the tumor (surgery, chemotherapy, radiotherapy, hormonal therapy, or other), multi-treatment ( $\geq 2 /<2$ cancer treatments), comorbidities $(\geq 2 /<2)$, post-cancer treatment weight gain/loss (gain, stable, loss), residential circumstances (alone or cohabitating), educational level (high, middle, or low), and employment status (employed or unemployed).

Moreover, patient-reported outcomes (PROs) were included in patient characteristics.

\section{Patient-reported outcomes (PROs)}

QoL The European Organization for Research and Treatment of Cancer Quality of Life Questionnaire (EORTC QLQ-C30) [93] was used to measure the QoL of the patients. A measurement model for the QLQ-C30 that yields a single summary score based on 13 scales (27 items) was also calculated [94].

Fatigue The Multidimensional Fatigue Inventory-20 (MFI20) questionnaire $[95,96]$ was used to measure patient fatigue.

Patient empowerment Patient empowerment was defined as the individual knowledge, skills, and confidence for managing the patient's own health and healthcare. The state of patient empowerment was measured using the patient activity measurement-13 (PAM-13) [97, 98].

Cancer center characteristics The cancer center characteristics were type of hospital (categorical, university, teaching, and non-teaching), Multidisciplinary Oncological Rehabilitation Board (MORB) available (yes or no), standardized screening with DT (yes or no), and PCRP in cancer center or connected cancer center available (internally, externally, or not at all). A MORB is a group of HCPs involved in oncological rehabilitation (e.g., surgeons, radiotherapists, medical oncologists, gynecologists, urologists, rehabilitation physicians, sportsmedicine physicians, physiotherapists, physician assistants, nurses, and psychologists) interacting dynamically, interdependently, and adaptively toward common, valued rehabilitation plans for the patients.

\section{Data analysis}

We used the Statistical Package for the Social Sciences (IBM SPSS Statistics version 22 for Windows; SPSS, Chicago, IL, USA) to enter the collected data in a database. We used descriptive analyses (frequencies, percentages, means, and SD or median and interquartile ranges) to describe patient characteristics and the scores for adherence to the indicators.

To determine whether our data were normally distributed, we examined the distribution of our continuous outcome measures and carried out quantile-quantile (Q-Q) plots. We also calculated the skewness and kurtosis of these variables. For all variables, both values of the skewness and kurtosis were between -1 and +1 , and Q-Q plots showed a straight line; therefore, they met normality requirements.

Because of the hierarchical structure of the study (patients nested within cancer centers), we performed multilevel analyses. We used univariate multilevel analyses for the indicators; the indicators were used as dependent variables. The characteristics of the patients and cancer centers were used as independent variables. Variables with $P<0.20$ in the univariate multilevel analysis were selected for the multilevel multivariate analysis. Collinearity among independent variables was tested with either a Pearson or Spearman correlation. If two independent variables (rho $>0.6$ ) correlated strongly, only the most clinically relevant characteristic was included. Multicollinearity was tested with the variance inflation factor, with values greater than 10 indicating multicollinearity.

We wanted to assess the extent to which the indicator scores could be explained by characteristics of (1) cancer centers, but also (2) the patients who were treated in these cancer centers, while taking the clustering of data into account. Our dataset contains information at the patient level from nine different cancer centers for each indicator.

For this purpose, we used SAS software (SAS 9.2 for Windows; SAS Institute, Cary, North Carolina, USA) for our multilevel multivariable regression analyses. We used the Glimmix procedure for dichotomous data and the MIXED procedure for continuous data to determine (1) the association between the scores of the indicators and patient and cancer center characteristics, and (2) the association between proper screening and the other indicators. The other indicators were information provision concerning PA and 
PCRPs, advice to take part in PA and PCRPs, referral to PCRPs, participation in PCRPs and PAU. The patient characteristics were included in the model as confounders in the analysis.

Multilevel models were used because these models take into consideration the variability associated with each level of nesting and the within-patient correlation. In these analyses, it was assumed that the patient (level 1) nested within the cancer center (level 2). We ran a model with a random intercept and all other variables fixed. Significance for multivariate analyses was set at $P<0.05$, based on two-sided testing. Odds ratios (OR) and $95 \%$ confidence intervals $(95 \% \mathrm{CI})$ were used to describe (1) the association between the scores of the indicators and patient and cancer center characteristics, and (2) the association of proper screening and the other indicators.

The intra-class coefficient (ICC) was calculated for each outcome to obtain insight into the clustering effect of the cancer centers.

\section{Results}

Nine cancer centers and their patients were recruited and included in the study. Of the 2069 patients who matched the inclusion criteria invited, 1211 patients (59\%) responded, and 999 patients (48\%) agreed to participate and gave informed consent.

\section{Patient and cancer center characteristics}

The mean age of the participants was 66.3 years; $60.7 \%$ were female and $94 \%$ had a Dutch background. The participants had a history of cancer of the breast $(31.1 \%)$, female organs (16.0\%), urogenital organs (23.6\%), gastrointestinal $(27.7 \%)$, and hematological malignancies (1.5\%). Eighty-five percent had undergone surgery, $39.8 \%$ received chemotherapy, $42.1 \%$ radiotherapy, and $21.7 \%$ hormonal therapy. Fifty-nine percent had received two or more cancer treatments and $31.7 \%$ had two or more comorbidities. Post-cancer treatment, $36.4 \%$ gained and $13.2 \%$ lost weight, while $50.4 \%$ kept a stable weight. Of the participants, $80.5 \%$ were cohabiting. As level of education, $38.3 \%$ of patients have finished low, $40.4 \%$ middle, and $21.2 \%$ a higher level of education and $25 \%$ were employed. The mean Global Health Status score was 77.5 (SD 18.0), the mean physical function score was 82.5 (SD 18.3), and the mean EORTC-QLQ-C30 summary score was 40.8 (SD 5.4). The Mean General Fatigue score was 10 (SD 4.6) and the Mean Physical Fatigue score was 9.6 (SD 4.4). The mean PAM-13 Total Score was 55.9 (SD 13.1).

In the study, one categorical, two university, two teaching, and four non-teaching hospitals participated related to respectively $5.5,20.5,25.2$, and $48.7 \%$ of the accrued patients. One center had a MORB available. Five hospitals performed standardized screening with the DT. Eight hospitals delivered a PCRP, of which four hospitals delivered internally and four hospitals externally.

Table 1 outlines the characteristics of the patients treated for the various types of cancer. Table 2 outlines the characteristics of the nine cancer centers.

\section{Indicator adherence}

The score of screening with the DT was $47.2 \%$. Information provision concerning PA and PCRPs scored $44.1 \%$, advice to take part in PA and PCRPs scored 55.6\%, referral to PCRPs scored $17.7 \%$, participation in PCRPs scored $28.6 \%$, and PAU scored $45.3 \%$. The indicator scores were higher for the patients who were screened with the DT. Information provision concerning PA and PCRPs scored $55.7 \%$ vs. $33.5 \%$, advice to take part in PA and PCRPs $67.0 \%$ vs. $45.3 \%$, referral to PCRPs $24.7 \%$ vs. $11.5 \%$, participation in PCRPs $38.1 \%$ vs. $20.2 \%$, and PAU $54.0 \%$ vs. $37.3 \%$ for respectively patients screened with the DT versus patients not screened with the DT. Screening with the DT was significantly associated with improved information provision concerning PA and PCRPs (OR 1.99, 95\% CI 1.47-2.71), advice to take part in PA and PCRPs (OR 1.79, 95\% CI 1.31-2.45), referral to PCRPs (OR 1.81, 95\% CI 1.18-2.78), participation in PCRPs (OR 2.04, 95\% CI 1.43-2.91), and PAU (OR 1.69, 95\% CI 1.25-2.29). Table 3 shows the effect of screening with the DT on the other indicators.

\section{Determinant analysis}

The indicator for screening with the DT scored significantly higher with the determinants younger age, female gender, breast cancer as type of tumor, two or more cancer treatments, and post-cancer treatment weight gain/loss.

The determinants younger age, male gender, and breast cancer as type of tumor resulted in significant higher scores of information provision concerning PA and PCRPs.

The determinants two or more cancer treatments, postcancer treatment weight gain, employment, and higher MFI20 mean general fatigue scores resulted in significant higher scores of advice to take part in PA and PCRPs.

The determinants younger age, male gender, breast cancer as type of tumor, two or more cancer treatments, post-cancer treatment weight gain, and higher MFI-20 mean general fatigue scores resulted in significant higher scores of referral to PCRPs.

The determinants younger age, male gender, breast cancer as type of tumor, post-cancer treatment weight gain, and higher MFI-20 mean general fatigue scores resulted in significant higher scores of participation in PCRPS.

The determinants younger age and post-cancer treatment weight gain/loss resulted in higher scores of $P A U$. 
Table 1 Characteristics of the patients

\begin{tabular}{|c|c|c|c|}
\hline & Total & Screened with DT & Not screened with DT \\
\hline Number of patients & 999 & 468 & 524 \\
\hline \multicolumn{4}{|l|}{ Characteristics } \\
\hline \multicolumn{4}{|l|}{ Age in years } \\
\hline \multirow[t]{3}{*}{ Mean (SD) } & $66.3(11.4)$ & $63.1(11.6)$ & $69.0(10.4)$ \\
\hline & Total & Screened with DT & Not screened with DT \\
\hline & Number of patients $(\% *)$ & Number of patients $(\% *)$ & Number of patients $(\% *)$ \\
\hline Female gender & $595(60.7)$ & $345(74.5)$ & $248(48.4)$ \\
\hline Dutch nationality & $913(93.5)$ & $429(93.4)$ & $480(93.4)$ \\
\hline \multicolumn{4}{|l|}{ Tumor type } \\
\hline Breast & $311(31.1)$ & $207(44.2)$ & $103(19.7)$ \\
\hline Female organs & $160(16.0)$ & $81(17.3)$ & $78(14.9)$ \\
\hline Urogenital organs & $236(23.6)$ & $66(14.1)$ & $169(32.3)$ \\
\hline Gastrointestinal & $277(27.7)$ & $104(22.2)$ & $169(32.3)$ \\
\hline Hematological malignancies & $15(1.5)$ & $10(2.1)$ & $5(1.0)$ \\
\hline \multicolumn{4}{|l|}{ Previously received treatment } \\
\hline Surgery & $844(84.5)$ & $421(90.0)$ & 417 (79.6) \\
\hline Chemotherapy & $398(39.8)$ & $235(50.2)$ & $159(30.3)$ \\
\hline Radiotherapy & $421(42.1)$ & $228(48.7)$ & $191(36.5)$ \\
\hline Hormonal therapy & $217(21.7)$ & $133(28.4)$ & $83(15.8)$ \\
\hline Other & $53(5.3)$ & $20(4.3)$ & $33(6.3)$ \\
\hline$\geq 2$ cancer treatments & $590(59.1)$ & $328(70.1)$ & $258(49.2)$ \\
\hline$\geq 2$ comorbidities & $317(31.7)$ & $167(35.7)$ & $149(28.4)$ \\
\hline \multicolumn{4}{|l|}{ Post-cancer treatment weight gain/loss } \\
\hline Gain & $353(36.4)$ & $193(42.1)$ & $157(31.0)$ \\
\hline Stable & $489(50.4)$ & $194(42.4)$ & $294(58.0)$ \\
\hline Loss & $128(13.2)$ & $71(15.5)$ & $56(11.0)$ \\
\hline Cohabiting & $799(80.5)$ & $380(81.9)$ & $416(79.7)$ \\
\hline \multicolumn{4}{|l|}{ Educational level } \\
\hline Low & $379(38.3)$ & 169 (36.6) & $205(39.4)$ \\
\hline Middle & $400(40.4)$ & $197(42.6)$ & $201(38.7)$ \\
\hline High & $210(21.2)$ & $96(20.8)$ & $114(21.9)$ \\
\hline Employed & $246(25.3)$ & 141(30.9) & $104(20.4)$ \\
\hline \multicolumn{4}{|l|}{ Department type } \\
\hline Categorical & $55(5.5)$ & $27(5.8)$ & $27(5.2)$ \\
\hline University & $205(20.5)$ & $76(16.2)$ & $129(24.6)$ \\
\hline Teaching & $252(25.2)$ & $108(23.1)$ & $142(27.1)$ \\
\hline Non-teaching & $487(48.7)$ & $257(54.9)$ & $226(43.1)$ \\
\hline \multicolumn{4}{|l|}{ EORTC-QLQ-C30 } \\
\hline Global Health Status/QoL (SD) & $77.5(18.0)$ & $77.5(17.4)$ & $77.5(18.5)$ \\
\hline Physical function (SD) & $82.5(18.3)$ & $82.1(17.9)$ & $82.9(18.8)$ \\
\hline Mean summary score (SD) & $40.8(5.4)$ & $40.7(5.4)$ & $40.8(5.4)$ \\
\hline \multicolumn{4}{|l|}{ MFI-20 score } \\
\hline Mean general fatigue (SD) & $10.0(4.6)$ & $10.5(4.5)$ & $9.6(4.6)$ \\
\hline Mean physical fatigue (SD) & $9.6(4.4)$ & $9.9(4.3)$ & $9.3(4.4)$ \\
\hline \multicolumn{4}{|l|}{ PAM-13 } \\
\hline Mean total score (SD) & $55.9(13.1)$ & $56.4(12.5)$ & $55.6(13.7)$ \\
\hline
\end{tabular}

DT, Distress Thermometer; EORTC QLQ-C30, The European Organization for Research and Treatment of Cancer Quality of Life Questionnaire; MFI20, Multidimensional Fatigue Inventory-20; PAM-13, Patient Activity Measurement-13

*valid percentage 
Table 2 Characteristics of the cancer centers

Number of facilities $\quad$ Center 1 Center 2 Center 3 Center 4 Center 5 Center 6 Center 7 Center 8 Center 9

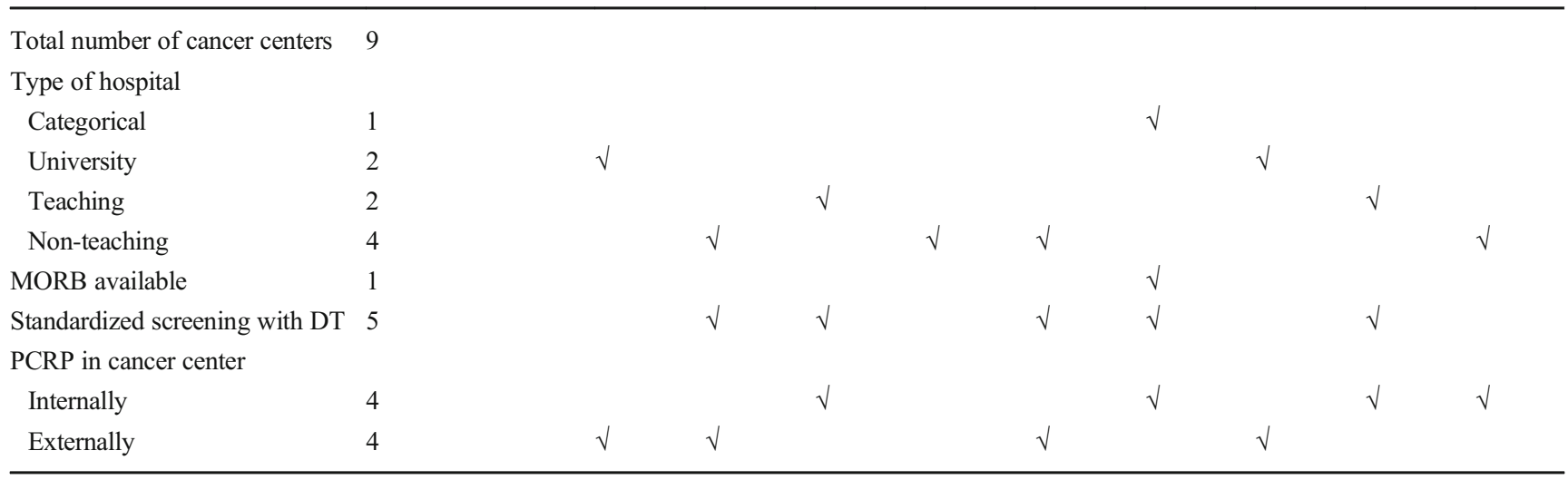

DT, Distress Thermometer; MORB, Multidisciplinary Oncological Rehabilitation Board; PCRP, physical cancer rehabilitation program

Table 4 shows multilevel associations of patient characteristics with the measured indicators.

Univariate and multivariable multilevel regression analyses were performed but showed less variation in scores of the indicators between the different cancer centers. The ICCs of the outcomes varied between 0 and 0.085 . This means that maximum $8.5 \%$ of the variation in an indicator could be explained by differences between cancer centers. This variation between centers was too low to detect any association between center characteristics (such as type of hospital, availability of a MORB, existence of standardized DT screening, and existence of PCRPs) with the indicators.

\section{Discussion}

In this observational study, we investigated the adherence to PCR guideline-based indicators and analyzed the associated determinants. We found less than $50 \%$ adherence for indicators on screening with the DT, information provision concerning PA and PCRPs, referral to PCRPs, participation in PCRPs, and PAU. Only the indicator for advice to take part in PA and PCRPs scored higher than 50\%. Screening with the DT was significantly associated with higher scores of all other indicators. Younger age, male gender, breast cancer as type of tumor, two or more cancer treatments, post-cancer treatment weight gain/loss, employment, and higher scores on MFI-20 mean general fatigue score were positively associated with higher indicator scores. The variation in center characteristics was too low to detect any association with the indicators.

Knowledge and understanding of the determinants of adherence to evidence-based PCR guideline-based indicators in the present study, together with previously published studies assessing the barriers of adherence to evidence-based PCR guidelines [77, 78], can assist HCPs in developing tailored strategies which can lead to improved adherence to PCR guidelines [75] by considering current practice as well as determinants of and barriers to adherence.

\section{Screening with the DT}

Screening is a key aspect in the delivery of healthcare. Patients who will accept and benefit from rehabilitation programs can be identified and encouraged to participate in PCRPs by using

Table 3 Effect of screening with Distress Thermometer on other indicator scores in the multilevel analysis

\begin{tabular}{|c|c|c|c|c|c|c|c|}
\hline \multirow[t]{2}{*}{ Effect of screening with Distress Thermometer on } & \multirow[t]{2}{*}{ Number of patients } & \multicolumn{3}{|c|}{ Uncorrected } & \multicolumn{3}{|c|}{ Corrected for confounders** } \\
\hline & & OR & $95 \% \mathrm{CI}$ & $P$ value* & OR & $95 \% \mathrm{CI}$ & $P$ value* \\
\hline Information provision concerning PA and PCRPs & 856 & 2.28 & 1.72 to 3.01 & $<0.0001$ & 1.99 & 1.47 to 2.71 & $<0.0001$ \\
\hline Advice to take part in PA and PCRPs & 868 & 2.33 & 1.76 to 3.08 & $<0.0001$ & 1.79 & 1.31 to 2.45 & 0.0003 \\
\hline Referral to PCRPs & 866 & 2.61 & 1.80 to 3.78 & $<0.0001$ & 1.81 & 1.18 to 2.78 & 0.0067 \\
\hline PCRP participation & 865 & 2.64 & 1.93 to 3.61 & $<0.0001$ & 2.04 & 1.43 to 2.91 & $<0.0001$ \\
\hline PAU & 867 & 2.16 & 1.64 to 2.84 & $<0.0001$ & 1.69 & 1.25 to 2.29 & 0.0007 \\
\hline
\end{tabular}

CI, confidence interval; OR, odds ratio; PA, physical activity; PCRP, physical cancer rehabilitation program; PAU, physical activity uptake

*The patient characteristics age, gender, comorbidities $(\geq 2 /<2)$, tumor type, multi-treatment $(\geq 2 /<2)$, weight change after cancer treatment, work status, and the outcome of the Multidimensional Fatigue Inventory- 20 were included in the model as confounders in the multilevel analysis 
Table 4 Patient characteristics and their association with the indicator scores in the multilevel analysis

Received screening with Distress Thermometer
Age
Male
Tumor type
Breast
Female organs
Urogenital organs
Gastrointestinal
$\geq 2$ cancer treatments
Post-cancer treatment weight gain/loss
Stable
Gain
Loss
Received information provision concerning PA and PCRPs

Received information provision concerning PA and PCRPs

$$
\begin{aligned}
& \text { Age } \\
& \text { Male } \\
& \text { Tumor type } \\
& \text { Breast } \\
& \text { Female organs } \\
& \text { Urogenital organs }
\end{aligned}
$$

Received advice to take part in PA and PCRPs

$\geq 2$ cancer treatments

Post-cancer treatment weight gain/loss

Stable

Gain

\title{
Employed
}

MFI-20 - mean general fatigue score

\section{Received referral to PCRPs}

\author{
Age \\ Male \\ Tumor type \\ Breast \\ Female organs \\ Urogenital organs \\ Gastrointestinal \\ $\geq 2$ cancer treatments \\ Post-cancer treatment weight gain/loss \\ Stable \\ Gain \\ MFI-20 - mean general fatigue score \\ Participated in PCRPs
}

Number of patients 992

\begin{tabular}{|c|c|c|c|}
\hline \multirow{14}{*}{$\begin{array}{l}\text { Number of patients } \\
992\end{array}$} & OR & $95 \% \mathrm{CI}$ & $P$ value* \\
\hline & & & \\
\hline & 0.96 & 0.95 to 0.98 & $<0.0001$ \\
\hline & 0.57 & 0.36 to 0.91 & 0.0194 \\
\hline & & & 0.0011 \\
\hline & 1.00 & & \\
\hline & 0.39 & 0.21 to 0.73 & 0.0031 \\
\hline & 0.30 & 0.15 to 0.63 & 0.0014 \\
\hline & 0.46 & 0.28 to 0.75 & 0.0019 \\
\hline & 1.44 & 1.04 to 2.00 & 0.0300 \\
\hline & & & 0.0245 \\
\hline & 1.00 & & \\
\hline & 1.46 & 1.06 to 2.01 & 0.0222 \\
\hline & 1.63 & 1.04 to 2.54 & 0.0316 \\
\hline \multirow{8}{*}{$\begin{array}{l}\text { Number of patients } \\
968\end{array}$} & OR & $95 \% \mathrm{CI}$ & $P$ value* \\
\hline & & & \\
\hline & 0.97 & 0.96 to 0.98 & $<0.0001$ \\
\hline & 1.63 & 1.04 to 2.56 & 0.0344 \\
\hline & & & $<0.0001$ \\
\hline & 1.00 & & \\
\hline & 0.40 & 0.26 to 0.60 & $<0.0001$ \\
\hline & 0.29 & 0.17 to 0.51 & $<0.0001$ \\
\hline \multirow{8}{*}{$\begin{array}{l}\text { Number of patients } \\
989\end{array}$} & OR & $95 \% \mathrm{CI}$ & $P$ value ${ }^{*}$ \\
\hline & & & \\
\hline & 2.01 & 1.48 to 2.72 & $<0.0001$ \\
\hline & & & $<0.0001$ \\
\hline & 1.00 & & \\
\hline & 2.07 & 1.50 to 2.85 & $<0.0001$ \\
\hline & 2.00 & 1.42 to 2.80 & $<0.0001$ \\
\hline & 1.08 & 1.05 to 1.12 & $<0.0001$ \\
\hline \multirow{14}{*}{$\begin{array}{l}\text { Number of patients } \\
982\end{array}$} & OR & $95 \% \mathrm{CI}$ & $P$ value ${ }^{*}$ \\
\hline & & & \\
\hline & 0.98 & 0.96 to 1.00 & 0.0137 \\
\hline & 3.26 & 1.56 to 6.82 & 0.0018 \\
\hline & & & 0.0020 \\
\hline & 1.00 & & \\
\hline & 0.33 & 0.14 to 0.77 & 0.0107 \\
\hline & 0.13 & 0.04 to 0.37 & 0.0002 \\
\hline & 0.31 & 0.15 to 0.65 & 0.0020 \\
\hline & 2.25 & 1.36 to 3.73 & 0.0016 \\
\hline & & & 0.0011 \\
\hline & 1.00 & & \\
\hline & 2.11 & 1.39 to 3.20 & 0.0005 \\
\hline & 1.07 & 1.02 to 1.11 & 0.0027 \\
\hline \multirow{6}{*}{$\begin{array}{l}\text { Number of patients } \\
978\end{array}$} & OR & $95 \% \mathrm{CI}$ & $P$ value \\
\hline & & & \\
\hline & 0.98 & 0.96 to 1.00 & 0.0009 \\
\hline & 1.92 & 1.08 to 3.41 & 0.0265 \\
\hline & & & 0.0003 \\
\hline & 1.00 & & \\
\hline
\end{tabular}

Number of patients 989

\footnotetext{
Age

Male

Tumor type

Breast
} 
Table 4 (continued)

\begin{tabular}{|c|c|c|c|c|}
\hline Female organs & & 0.38 & 0.21 to 0.69 & 0.0017 \\
\hline Urogenital organs & & 0.22 & 0.10 to 0.48 & 0.0001 \\
\hline Gastrointestinal & & 0.34 & 0.19 to 0.60 & 0.0002 \\
\hline Post-cancer treatment weight gain/loss & & & & $<0.0001$ \\
\hline Stable & & 1.00 & & \\
\hline Gain & & 2.08 & 1.47 to 2.94 & $<0.0001$ \\
\hline MFI-20- mean general fatigue score & & 1.10 & 1.06 to 1.14 & $<0.0001$ \\
\hline Increase in PAU & $\begin{array}{l}\text { Number of patients } \\
992\end{array}$ & OR & $95 \% \mathrm{CI}$ & $P$ value* \\
\hline Age & & 0.97 & 0.95 to 0.98 & $<0.0001$ \\
\hline Post-cancer treatment weight gain/loss & & & & 0.0002 \\
\hline Stable & & 1.00 & & \\
\hline Gain & & 1.60 & 1.20 to 2.14 & 0.0016 \\
\hline Loss & & 2.12 & 1.40 to 3.20 & 0.0004 \\
\hline
\end{tabular}

CI, confidence interval; OR, odds ratio; MFI, Multidimensional Fatigue Inventory-20; PA, physical activity; PCRP, physical cancer rehabilitation program; PAU, physical activity uptake

*Valid percentage

the DT $[59,60]$. Encouraging screening with the DT in daily cancer care will help promote the implementation of PCR guidelines. In our study, $47 \%$ of the patients were screened with the DT. Other studies found comparable percentages of screening with the DT of 40-50\% [99]. The score of screening with the DT shows room for improvement, especially because the screening was significantly positively associated with higher scores of the other indicators, with ORs between 1.69 and 2.04. Therefore, encouraging screening with the DT is a good first step toward improving adherence to the current PCR guidelines.

\section{Determinants}

This is one of the first studies to investigate determinants at the patient and cancer center levels for PCR guideline-based indicators. Other studies examining determinants of guideline adherence have been carried out in several other areas of cancer care, including treatment guidelines for lung, prostate, and gastrointestinal cancers. They found low guideline adherence rates and differences in delivered care associated with hospital type and patient age, gender, and disease stage [100-103] as well as educational level $[104,105]$ and employment status [106]. In addition, implementation strategies developed with knowledge of determinants in these other areas of cancer care did achieve improvement of guideline adherence. Therefore, knowledge of determinants is useful in creating tailored strategies for implementing PCR guidelines.

We detected a higher screening score for women, but higher scores for information provision, referral, and participation in PCRPs for men. Gender disparity in the use of cancer rehabilitation care and other healthcare services has been noted before in the literature [83, 107-109].

Traditional notions of masculinity that emphasize the values of being autonomous and less emotional may lead men to be reluctant to express emotion or distress
[110-112]. In addition to the higher levels of media attention being paid to the post-cancer physical and psychosocial symptoms experienced by women, HCPs might be influenced by gender bias and less aware of screening men for distress. Men also seem to be more eager for sufficient explanations concerning screening in order to make a decision to participate $[56,57]$.

Besides screening, gender bias has been reported to affect HCP referral and treatment decisions and may also influence decisions on advising women for increasing PA or referral to PCRPs [113-115]. Women's gender-specific roles and PA preferences may also contribute to women not participating in PCRPs. Contemporary the burden of cancer is evenly distributed between the different sexes. Currently, one in five men and one in six women will be diagnosed with cancer [116]; therefore, attention should be paid to improve screening of males, and improving information provision and referrals to PCRPs for female survivors of cancer. We did not distinguish our strategies on sex in our research. Future research can be used to differentiate which strategies are more effective for men and women.

We also found tumor type to be a determinant. Patients with breast cancer receive more screening, information, and referral to PCRPs, and they participate more in PCRPs. Indicator scores were lower for patients with a history of female organ, urogenital organ, and gastrointestinal malignancies. One reason for this is that most initiatives for improving PCR guideline adherence are designed for and focused on breast cancer. Screening of patients with breast cancer with the DT was relatively well adhered to, as not screening means no accreditation for breast cancer care as required by the patient organization for patients with breast cancer. Patients with gastrointestinal and female organ malignancies judge their cancer care to be of lower quality than that of patients with other tumor types [117]. After completing their primary treatment, patients with gastrointestinal malignancies also rated the 
information provided as significantly lower in quality than that of patients with breast cancer [118]. Worldwide, malignancies of the gastrointestinal, reproductive, and urogenital systems account for approximately $35 \%$ of all malignancies, which is three times the incidence of breast cancer $[119,120]$. Therefore, it might be beneficial to preferably focus the strategy on cancer patients and their HCPs in the care pathways for gastrointestinal, female organ, and urogenital organ oncology.

The recruitment of patients with abdominopelvic cavity tumors to PCRPs is difficult $[7,8,26,121]$. HCPs are more hesitant to refer patients who have undergone major abdominal surgery to PCRPs and typically advise patients to refrain from PA for a number of weeks after surgery [7]. Teaching the HCPs about the positive associations of PA with less physical and psychosocial symptoms and even improved mortality [33, 34, 122-124] might be a good strategy. In addition, tailored PA guidelines need to be developed since these patients require different PCRPs due to a different range of morbidities and needs. The introduction of accreditation for PCR guideline-based care that has proved successful for patients with breast cancer into the pathways for gastrointestinal, female organ, and urogenital organ oncology might be another strategy.

Two or more cancer treatments showed to be a determinant. Patient with fewer treatments overall have fewer visits to the cancer center and encounter fewer HCPs who provide them PCR guideline-based care. For all treatment modalities, it should be clear when, who, and where the PCR care is delivered, preferably stated in a treatment protocol. PCRPs delivered through practical avenues such as print materials, telephone counseling, and web-based programs are an alternative [125-129] for patients with fewer visits to the cancer center. Web-based PCRPs with online encouragement, online diaries, and online physical activity programs proved to be feasible with median vigorous PAU over time, and the burden for HCPs appeared to be limited [130-132].

Patients with post-cancer treatment weight gain/loss had better adherence to PCR guideline-based indicators. Cancer patients experience weight changes due to the cancer itself or to the cancer treatments, such as loss of muscular mass and increased fat mass [133-136]. The weight change might be the reason for paying more attention to PCR. A referral to a dietician might more readily lead patients to PCRPs as a means of returning to their old weight. In addition, PA is one of the main treatments for weight imbalance since it reduces fat mass and improves muscle mass and has a potential role in preventing and treating cachexia [136, 137].

The ORs of age being 0.96-0.98 and ORs of the MFI-20 mean general score being $1.07-1.10$ are numerically very close to an OR of 1.00. The absolute influence of the determinants age and fatigue (the MFI-20 mean general score) on the indicator scores will therefore be negligible and not clinically relevant.
However, a higher age has previously been found to be associated with negative patterns in delivered care and lower levels of PA [138-142]. In addition, most cancer patients have higher fatigue scores [95], and fatigue is a common and debilitating side effect of cancer and its treatment [143]. It is known that PA can reduce fatigue after the treatment of cancer [144]. More research is necessary to explore the additional effect of strategies focusing on patients with fatigue and of a higher age.

\section{Strengths and limitations}

Our study has several strengths. One is that we thoroughly followed the RAND-modified Delphi method [89, 90], which led to the discovery of valid indicators which formed an important basis for measuring guideline-based PCR care. Another is the large study sample of 999 patients, which might have contributed to a reliable dataset for the investigation of the adherence and the analysis of the determinants associated with optimal PCR care.

There are also some limitations which need to be addressed; for example, possible selection bias. Only patients of cancer centers who were willing to participate in our study were included. One can assume these patients have better adherence to PCR guideline-based indicators since these centers are more dedicated to improving this aspect of cancer care. Thus, we expect lower indicator scores in centers less committed to achieving this goal. Further research should also include patients from cancer centers not motivated to implement PCRPs.

One could expect that also organizational characteristics would be associated with performance on indicators related to the provision of distress screening and rehabilitation programs to cancer survivors. Univariate and multivariable multilevel regression analyses showed less variation in scores of the indicators between the different cancer centers. The ICC is calculated as the ratio of the between variance and the total variance (between and within variance). The ICC gives information of the degree of correlation among patients within a cancer center and the proportion of total variance that is attributed to the cluster level (cancer centers). The ICCs of the outcomes varied between 0 and 0.085 . This means that maximum $8.5 \%$ of the variation in an indicator could be explained by differences between cancer centers, predicting a low chance of between-cluster variability. This variation between centers was too low to detect any association between center characteristics with the indicators. This might be caused by the limited sample size of nine cancer centers and the variation in characteristics between them, indicating that participation of more centers with more variation in characteristics is needed in future research to analyze cancer centers' characteristics associated with the indicators. 
Possible determinants influencing PCR guideline implementation often arise at multiple levels in the healthcare system (patient, HCPs, cancer center, and healthcare organization levels). Currently, cancer care is frequently provided by a multidisciplinary team of HCPs situated in a cancer center. This results in interactive, coordinated care; therefore, we only explored determinants of the cancer centers. However, there may be compelling reasons for both lack of adherence and adherence due to determinants of the individual HCPs, particularly because HCPs' limited knowledge and skill levels, negative approach, non-commitment to PCRPs, difference in attitude about timing and strategies for cancer rehabilitation, and fear of additional workload all hinder proper PCR care [77, $78,145,146]$. On the level of the referring providers, limited knowledge levels concerning PCRPs and PCR guidelines hinder proper screening of patients. Moreover, lack of knowledge and skills among HCPs resulted in a lack of qualified information provision for the patients. It also resulted in a lack of guidance in finding the right PCRP and a successful referral for joining the PCRP, both being barriers that impede proper PCR care $[77,78,145,146]$.

\section{Conclusions}

Our study highlights the need for improvement in the implementation of PCR guidelines. It demonstrates that there are numerous determinants at the patient level associated with PCR guideline-based indicators. To ascertain cancer center determinants, more cancer centers with greater variation in characteristics are needed in future research. We discovered that screening with the DT is significantly positively associated with higher indicator scores and should be the first step in any successful implementation. The next step is developing and evaluating an implementation strategy based on knowledge of the determinants.

Funding This work was supported by the Dutch Cancer Society (grant no. NKI 2010-4854).

Availability of data and materials All data generated or analyzed in the present study are included in this published article and its supplementary information files.

\section{Compliance with ethical standards}

Competing interests and disclosure The authors declare that they have no conflicts of interest.

Ethics approval and consent to participate The regional review board for human research assessed the study (CMO Arnhem-Nijmegen dossier number 2014/211) and judged that ethics approval was not required under Dutch national law. The study was performed in accordance with the privacy legislation. Informed consent was obtained from all individual participants included in the study.
Consent for publication Not applicable

Open Access This article is licensed under a Creative Commons Attribution 4.0 International License, which permits use, sharing, adaptation, distribution and reproduction in any medium or format, as long as you give appropriate credit to the original author(s) and the source, provide a link to the Creative Commons licence, and indicate if changes were made. The images or other third party material in this article are included in the article's Creative Commons licence, unless indicated otherwise in a credit line to the material. If material is not included in the article's Creative Commons licence and your intended use is not permitted by statutory regulation or exceeds the permitted use, you will need to obtain permission directly from the copyright holder. To view a copy of this licence, visit http://creativecommons.org/licenses/by/4.0/.

\section{References}

1. Lee IM, Shiroma EJ, Lobelo F, et al. Effect of physical inactivity on major non-communicable diseases worldwide: an analysis of burden of disease and life expectancy. Lancet. 2012;380(9838): 219-29.

2. Midtgaard J, Baadsgaard MT, Moller T, et al. Self-reported physical activity behaviour; exercise motivation and information among Danish adult cancer patients undergoing chemotherapy. Eur J Oncol Nurs. 2009;13(2):116-21.

3. Littman AJ, Tang MT, Rossing MA. Longitudinal study of recreational physical activity in breast cancer survivors. J Cancer Surviv. 2010;4(2):119-27.

4. Mishra SI, Scherer RW, Geigle PM, et al. Exercise interventions on health-related quality of life for cancer survivors. Cochrane Database Syst Rev. 2012;8:CD007566.

5. Cramp F, Byron-Daniel J. Exercise for the management of cancerrelated fatigue in adults. Cochrane Database Syst Rev. 2012;11: CD006145.

6. Markes M, Brockow T, Resch KL. Exercise for women receiving adjuvant therapy for breast cancer. Cochrane Database Syst Rev. 2006;4:CD005001.

7. van Waart H, Stuiver MM, van Harten WH, et al. Effect of lowintensity physical activity and moderate- to high-intensity physical exercise during adjuvant chemotherapy on physical fitness, fatigue, and chemotherapy completion rates: results of the PACES randomized clinical trial. J Clin Oncol. 2015;33(17):1918-27.

8. Kampshoff CS, Chinapaw MJ, Brug J, et al. Randomized controlled trial of the effects of high intensity and low-to-moderate intensity exercise on physical fitness and fatigue in cancer survivors: results of the resistance and endurance exercise after ChemoTherapy (REACT) study. BMC Med. 2015;13:275.

9. Scott DA, Mills M, Black A, et al. Multidimensional rehabilitation programmes for adult cancer survivors. Cochrane Database Syst Rev. 2013;3:CD007730.

10. Mishra SI, Scherer RW, Snyder C, Geigle PM, Berlanstein DR, Topaloglu O. Exercise interventions on health-related quality of life for people with cancer during active treatment. Cochrane Database Syst Rev. 2012;8:CD008465.

11. Speck RM, Courneya KS, Masse LC, Duval S, Schmitz KH. An update of controlled physical activity trials in cancer survivors: a systematic review and meta-analysis. J Cancer Surviv. 2010;4(2): $87-100$.

12. Ingram $\mathrm{C}$, Visovsky $\mathrm{C}$. Exercise intervention to modify physiologic risk factors in cancer survivors. Semin Oncol Nurs. 2007;23(4):275-84.

13. Schmitz KH, Holtzman J, Courneya KS, Masse LC, Duval S, Kane R. Controlled physical activity trials in cancer survivors: a 
systematic review and meta-analysis. Cancer Epidemiol Biomark Prev. 2005;14(7):1588-95.

14. Warburton DE, Nicol CW, Bredin SS. Health benefits of physical activity: the evidence. CMAJ. 2006;174(6):801-9.

15. Courneya KS, Friedenreich CM. Physical activity and cancer control. Semin Oncol Nurs. 2007;23(4):242-52.

16. Schmitz KH, Courneya KS, Matthews C, Demark-Wahnefried W, Galvão DA, Pinto BM, et al. American college of sports medicine roundtable on exercise guidelines for cancer survivors. Med Sci Sports Exerc. 2010;42(7):1409-26.

17. McNeely ML, Campbell KL, Rowe BH, Klassen TP, Mackey JR, Courneya KS. Effects of exercise on breast cancer patients and survivors: a systematic review and meta-analysis. CMAJ. 2006;175(1):34-41.

18. Schwartz AL, Mori M, Gao R, Nail LM, King ME. Exercise reduces daily fatigue in women with breast cancer receiving chemotherapy. Med Sci Sports Exerc. 2001;33(5):718-23.

19. Schwartz AL. Fatigue mediates the effects of exercise on quality of life. Qual Life Res. 1999;8(6):529-38.

20. Schwartz AL. Daily fatigue patterns and effect of exercise in women with breast cancer. Cancer Pract. 2000;8(1):16-24.

21. Kolden GG, Strauman TJ, Ward A, Kuta J, Woods TE, Schneider $\mathrm{KL}$, et al. A pilot study of group exercise training (GET) for women with primary breast cancer: feasibility and health benefits. Psychooncology. 2002;11(5):447-56.

22. Dimeo F, Stieglitz RD, Novelli-Fischer U, Fetscher S, Mertelsmann R, Keul J. Correlation between physical performance and fatigue in cancer patients. Ann Oncol. 1997;8(12): 1251-5.

23. Winningham ML. Strategies for managing cancer-related fatigue syndrome: a rehabilitation approach. Cancer. 2001;92(4 Suppl): 988-97.

24. National Comprehensive Cancer Network. Cancer-related fatigue. Clinical practice guidelines in oncology. J Natl Compr Cancer Netw. 2003;1(3):308-31.

25. Dimeo FC. Effects of exercise on cancer-related fatigue. Cancer. 2001;92(6 Suppl):1689-93.

26. Kampshoff CS, van Dongen JM, van Mechelen W, Schep G, Vreugdenhil A, Twisk JWR, et al. Long-term effectiveness and cost-effectiveness of high versus low-to-moderate intensity resistance and endurance exercise interventions among cancer survivors. J Cancer Surviv. 2018;12(3):417-29.

27. Knols R, Aaronson NK, Uebelhart D, Fransen J, Aufdemkampe G. Physical exercise in cancer patients during and after medical treatment: a systematic review of randomized and controlled clinical trials. J Clin Oncol. 2005;23(16):3830-42.

28. Courneya KS, Karvinen KH, McNeely ML, et al. Predictors of adherence to supervised and unsupervised exercise in the Alberta physical activity and breast cancer prevention trial. J Phys Act Health. 2012;9(6):857-66.

29. Courneya KS. Exercise in cancer survivors: an overview of research. Med Sci Sports Exerc. 2003;35(11):1846-52.

30. Young-McCaughan S, Sexton DL. A retrospective investigation of the relationship between aerobic exercise and quality of life in women with breast cancer. Oncol Nurs Forum. 1991;18(4):751-7.

31. Courneya KS, Friedenreich CM. Relationship between exercise pattern across the cancer experience and current quality of life in colorectal cancer survivors. J Altern Complement Med. 1997;3(3):215-26.

32. Galvao DA, Newton RU. Review of exercise intervention studies in cancer patients. J Clin Oncol. 2005;23(4):899-909.

33. Schmid D, Leitzmann MF. Association between physical activity and mortality among breast cancer and colorectal cancer survivors: a systematic review and meta-analysis. Ann Oncol. 2014;25(7):1293-311
34. Wu W, Guo F, Ye J, et al. Pre- and post-diagnosis physical activity is associated with survival benefits of colorectal cancer patients: a systematic review and meta-analysis. Oncotarget. 2016;7(32): 52095-103.

35. Campbell KL, Winters-Stone KM, Wiskemann J, et al. Exercise guidelines for cancer survivors: consensus statement from international multidisciplinary roundtable. Med Sci Sports Exerc. 2019;51(11):2375-90.

36. Patel AV, Friedenreich CM, Moore SC, et al. American College of Sports Medicine roundtable report on physical activity, sedentary behavior, and cancer prevention and control. Med Sci Sports Exerc. 2019;51(11):2391-402.

37. van den Berg JP, Velthuis MJ, Gijsen BC, Lindeman E, van der Pol MA, Hillen HF. Guideline "Cancer rehabilitation". Ned Tijdschr Geneeskd. 2011;155(51):A4104.

38. (NCCO) NCCO. Cancer surivorship care; Cancer clinical practice guidelines. 2018.

39. Runowicz CD, Leach CR, Henry NL, et al. American Cancer Society/American Society of Clinical Oncology Breast Cancer Survivorship Care Guideline. J Clin Oncol. 2016;34(6):611-35.

40. Resnick MJ, Lacchetti C, Penson DF. Prostate cancer survivorship care guidelines: American Society of Clinical Oncology practice guideline endorsement. J Oncol Pract. 2015;11(3):e445-9.

41. El-Shami K, Oeffinger KC, Erb NL, et al. American Cancer Society colorectal cancer survivorship care guidelines. CA Cancer J Clin. 2015;65(6):428-55.

42. Rock CL, Doyle C, Demark-Wahnefried W, Meyerhardt J, Courneya KS, Schwartz AL, et al. Nutrition and physical activity guidelines for cancer survivors. CA Cancer J Clin. 2012;62(4): 243-74.

43. Stout NL, Silver JK, Raj VS, Rowland J, Gerber L, Cheville A, et al. Toward a national initiative in cancer rehabilitation: recommendations from a subject matter expert group. Arch Phys Med Rehabil. 2016;97(11):2006-15.

44. NHS. Innovation to implementation: stratified pathways of care for people living with or beyond cancer. A 'how to guide'. 2016.

45. Wiedenbein L, Kristiansen M, Adamsen L, Hjort D, Hendriksen C. Assessment of rehabilitation needs in colorectal cancer treatment: results from a mixed audit and qualitative study in Denmark. Acta Oncol. 2016;55(6):705-11.

46. Tvede CF, Brandstrup B, Engholm G, Tonnesen H. Potential number of rehabilitated cancer patients in Denmark - an estimate. Ugeskr Laeger. 2003;165(2):123-8.

47. Thorsen L, Gjerset GM, Loge JH, Kiserud CE, Skovlund E, Fløtten T, et al. Cancer patients' needs for rehabilitation services. Acta Oncol. 2011;50(2):212-22.

48. Holm LV, Hansen DG, Johansen C, Vedsted P, Larsen PV, Kragstrup J, et al. Participation in cancer rehabilitation and unmet needs: a population-based cohort study. Support Care Cancer. 2012;20(11):2913-24.

49. Stevinson C, Fox KR. Feasibility of an exercise rehabilitation programme for cancer patients. Eur J Cancer Care (Engl). 2006;15(4):386-96.

50. Courneya KS, Mackey JR, Bell GJ, Jones LW, Field CJ, Fairey AS. Randomized controlled trial of exercise training in postmenopausal breast cancer survivors: cardiopulmonary and quality of life outcomes. J Clin Oncol. 2003;21(9):1660-8.

51. Segal R, Evans W, Johnson D, et al. Structured exercise improves physical functioning in women with stages I and II breast cancer: results of a randomized controlled trial. J Clin Oncol. 2001;19(3): 657-65.

52. Segal RJ, Reid RD, Courneya KS, et al. Resistance exercise in men receiving androgen deprivation therapy for prostate cancer. J Clin Oncol. 2003;21(9):1653-9. 
53. Canestraro A, Nakhle A, Stack M, Strong K, Wright A, Beauchamp M, et al. Oncology rehabilitation provision and practice patterns across Canada. Physiother Can. 2013;65(1):94-102.

54. Segal R, Evans W, Johnson D, et al. Oncology Rehabilitation Program at the Ottawa Regional Cancer Centre: program description. CMAJ. 1999;161(3):282-5.

55. Demark-Wahnefried W. Print-to-practice: designing tailored print materials to improve cancer survivors' dietary and exercise practices in the FRESH START trial. Nutr Today. 2007;42(3):131-8.

56. Grabois M. Integrating cancer rehabilitation into medical care at a cancer hospital. Cancer. 2001;92(4 Suppl):1055-7.

57. Schmidt KD. Cancer rehabilitation services in a tertiary care center. Cancer. 2001;92(4 Suppl):1053-4.

58. IJsbrandy C, Ottevanger PB, Tsekou Diogeni M, Gerritsen WR, van Harten WH, Hermens RPMG. Review: effectiveness of implementation strategies to increase physical activity uptake during and after cancer treatment. Crit Rev Oncol Hematol. 2018;122: 157-63.

59. Hermelink K, Hohn H, Hasmuller S, et al. Brief distress screening in clinical practice: does it help to effectively allocate psychooncological support to female cancer inpatients? Breast Care (Basel). 2014;9(2):129-33.

60. Chambers SK, Zajdlewicz L, Youlden DR, Holland JC, Dunn J. The validity of the distress thermometer in prostate cancer populations. Psychooncology. 2014;23(2):195-203.

61. Grol R. Personal paper. Beliefs and evidence in changing clinical practice. BMJ. 1997;315(7105):418-21.

62. Grol R, Grimshaw J. From best evidence to best practice: effective implementation of change in patients' care. Lancet. 2003;362(9391):1225-30.

63. Davis DA, Taylor-Vaisey A. Translating guidelines into practice. A systematic review of theoretic concepts, practical experience and research evidence in the adoption of clinical practice guidelines. CMAJ. 1997;157(4):408-16.

64. Bero LA, Grilli R, Grimshaw JM, Harvey E, Oxman AD, Thomson MA. Closing the gap between research and practice: an overview of systematic reviews of interventions to promote the implementation of research findings. The Cochrane Effective Practice and Organization of Care Review Group. BMJ. 1998;317(7156):465-8.

65. Berwick DM. Developing and testing changes in delivery of care. Ann Intern Med. 1998;128(8):651-6.

66. Grimshaw JM, Shirran L, Thomas R, Mowatt G, Fraser C, Bero L, et al. Changing provider behavior: an overview of systematic reviews of interventions. Med Care. 2001;39(8 Suppl 2):II2-45.

67. Kitson A, Harvey G, McCormack B. Enabling the implementation of evidence based practice: a conceptual framework. Qual Health Care. 1998;7(3):149-58.

68. Moulding NT, Silagy CA, Weller DP. A framework for effective management of change in clinical practice: dissemination and implementation of clinical practice guidelines. Qual Health Care. 1999;8(3):177-83.

69. National Health and Medical Research Council (NHMRC). How to put the evidence into practice: implementation and dissemination strategies. Canberra: Commonwealth of Australia; 2000.

70. Grol R. Improving the quality of medical care: building bridges among professional pride, payer profit, and patient satisfaction. JAMA. 2001;286(20):2578-85.

71. Kroenke K, Taylor-Vaisey A, Dietrich AJ, Oxman TE. Interventions to improve provider diagnosis and treatment of mental disorders in primary care. A critical review of the literature. Psychosomatics. 2000;41(1):39-52.

72. Wensing M, Bosch M, Grol R. Developing and selecting interventions for translating knowledge to action. CMAJ. 2010;182(2): E85-8.
73. Grol R, Wensing M. What drives change? Barriers to and incentives for achieving evidence-based practice. Med J Aust. 2004;180(6 Suppl):S57-60.

74. Baker R, Camosso-Stefinovic J, Gillies C, et al. Tailored interventions to overcome identified barriers to change: effects on professional practice and health care outcomes. Cochrane Database Syst Rev. 2010;(3):Cd005470.

75. IJsbrandy C, Ottevanger PB, Groen WG, Gerritsen WR, van Harten WH, Hermens RP. Study protocol: an evaluation of the effectiveness, experiences and costs of a patient-directed strategy compared with a multi-faceted strategy to implement physical cancer rehabilitation programmes for cancer survivors in a European healthcare system; a controlled before and after study. Implement Sci. 2015;10:128.

76. Grol R, Wensing M, Eccles M. Improving patient care: the implementation of change in clinical practice. 2005.

77. IJsbrandy C, Hermens RPMG, Boerboom LWM, Gerritsen WR, van Harten WH, Ottevanger PB. Implementing physical activity programs for patients with cancer in current practice: patients' experienced barriers and facilitators. J Cancer Surviv. 2019;13(5):703-12.

78. IJsbrandy C, van Harten WH, Gerritsen WR, Hermens R, Ottevanger PB. Healthcare professionals' perspectives of barriers and facilitators in implementing physical activity programmes delivered to cancer survivors in a shared-care model: a qualitative study. Support Care Cancer. 2020;28(7):3429-40.

79. Irwin ML. Physical activity interventions for cancer survivors. $\mathrm{Br}$ J Sports Med. 2009;43(1):32-8

80. Fine JM, Fine MJ, Galusha D, Petrillo M, Meehan TP. Patient and hospital characteristics associated with recommended processes of care for elderly patients hospitalized with pneumonia: results from the medicare quality indicator system pneumonia module. Arch Intern Med. 2002;162(7):827-33.

81. Schouten JA, Hulscher ME, Kullberg BJ, Cox A, Gyssens IC, van der Meer JW, et al. Understanding variation in quality of antibiotic use for community-acquired pneumonia: effect of patient, professional and hospital factors. J Antimicrob Chemother. 2005;56(3): 575-82.

82. Hermens RP, Haagen EC, Nelen WL, et al. Patient and hospital characteristics associated with variation in guideline adherence in intrauterine insemination care. Int J Qual Health Care. 2011;23(5): 574-82.

83. Stienen JJ, Hermens RP, Wennekes L, et al. Variation in guideline adherence in non-Hodgkin's lymphoma care: impact of patient and hospital characteristics. BMC Cancer. 2015;15:578.

84. van den Boogaard NM, Musters AM, Bruhl SW, Tankens T, Kremer JAM, Mol BWJ, et al. Tailored expectant management: a nationwide survey to quantify patients' and professionals' barriers and facilitators. Hum Reprod. 2012;27(4):1050-7.

85. van den Boogaard NM, Oude Rengerink K, Steures P, Bossuyt PM, Hompes PGA, van der Veen F, et al. Tailored expectant management: risk factors for non-adherence. Hum Reprod. 2011;26(7):1784-9.

86. Baker R, Camosso-Stefinovic J, Gillies C, et al. Tailored interventions to address determinants of practice. Cochrane Database Syst Rev. 2015;4:Cd005470.

87. Medisch specialistische revalidatie bij oncologie Landelijke richtlijn, Versie: 2.0. Integraal kankercentrum Nederland (IKNL); 01-03-2018 2018.

88. Cancer survivorship care nation-wide guideline, version: 1.0. 1702-2011 2011.

89. Hermens RP, Ouwens MM, Vonk-Okhuijsen SY, et al. Development of quality indicators for diagnosis and treatment of patients with non-small cell lung cancer: a first step toward implementing a multidisciplinary, evidence-based guideline. Lung Cancer. 2006;54(1):117-24. 
90. Mourad SM, Hermens RP, Nelen WL, Braat DD, Grol RP, Kremer JA. Guideline-based development of quality indicators for subfertility care. Hum Reprod. 2007;22(10):2665-72.

91. Tuinman MA, Gazendam-Donofrio SM, Hoekstra-Weebers JE. Screening and referral for psychosocial distress in oncologic practice: use of the Distress Thermometer. Cancer. 2008;113(4):870 8.

92. Holland JC, Bultz BD. The NCCN guideline for distress management: a case for making distress the sixth vital sign. J Natl Compr Cancer Netw. 2007;5(1):3-7.

93. Aaronson NK, Ahmedzai S, Bergman B, et al. The European Organization for Research and Treatment of Cancer QLQ-C30: a quality-of-life instrument for use in international clinical trials in oncology. J Natl Cancer Inst. 1993;85(5):365-76.

94. Giesinger JM, Kieffer JM, Fayers PM, Groenvold M, Petersen MA, Scott NW, et al. Replication and validation of higher order models demonstrated that a summary score for the EORTC QLQC30 is robust. J Clin Epidemiol. 2016;69:79-88.

95. Smets EM, Garssen B, Cull A, de Haes JC. Application of the multidimensional fatigue inventory (MFI-20) in cancer patients receiving radiotherapy. $\mathrm{Br} \mathrm{J}$ Cancer. 1996;73(2):241-5.

96. Smets EM, Garssen B, Bonke B, De Haes JC. The multidimensional fatigue inventory (MFI) psychometric qualities of an instrument to assess fatigue. J Psychosom Res. 1995;39(3):315-25.

97. Hibbard JH, Stockard J, Mahoney ER, Tusler M. Development of the patient activation measure (PAM): conceptualizing and measuring activation in patients and consumers. Health Serv Res. 2004;39(4 Pt 1):1005-26.

98. Hibbard JH, Mahoney ER, Stockard J, Tusler M. Development and testing of a short form of the patient activation measure. Health Serv Res. 2005;40(6 Pt 1):1918-30.

99. Gotz A, Kroner A, Jenewein J, Spirig R. Evaluation of the adherence of distress screening with the distress thermometer in cancer patients 4 years after implementation. Support Care Cancer. 2019;27(8):2799-807.

100. Ouwens MM, Hermens RR, Termeer RA, et al. Quality of integrated care for patients with nonsmall cell lung cancer: variations and determinants of care. Cancer. 2007;110(8):1782-90.

101. Mathoulin-Pelissier S, Becouarn Y, Belleannee G, et al. Quality indicators for colorectal cancer surgery and care according to patient-, tumor-, and hospital-related factors. BMC Cancer. 2012;12: 297.

102. Schroeck FR, Kaufman SR, Jacobs BL, Skolarus TA, Hollingsworth JM, Shahinian VB, et al. Regional variation in quality of prostate cancer care. J Urol. 2014;191(4):957-62.

103. Sacerdote C, Baldi I, Bertetto O, et al. Hospital factors and patient characteristics in the treatment of colorectal cancer: a population based study. BMC Public Health. 2012;12:775.

104. Oksbjerg Dalton S, Halgren Olsen M, Moustsen IR, Wedell Andersen C, Vibe-Petersen J, Johansen C. Socioeconomic position, referral and attendance to rehabilitation after a cancer diagnosis: a population-based study in Copenhagen, Denmark 2010 2015. Acta Oncol. 2019;58(5):730-6.

105. Moustsen IR, Larsen SB, Vibe-Petersen J, Trier K, Bidstrup PE, Andersen KK, et al. Social position and referral to rehabilitation among cancer patients. Acta Oncol. 2015;54(5):720-6.

106. Stone CR, Courneya KS, McGregor SE, Li H, Friedenreich CM. Determinants of changes in physical activity from pre-diagnosis to post-diagnosis in a cohort of prostate cancer survivors. Support Care Cancer. 2018

107. Razmjou H, Lincoln S, Macritchie I, Richards RR, Medeiros D, Elmaraghy A. Sex and gender disparity in pathology, disability, referral pattern, and wait time for surgery in workers with shoulder injury. BMC Musculoskelet Disord. 2016;17(1):401.
108. Fowler RA, Sabur N, Li P, et al. Sex- and age-based differences in the delivery and outcomes of critical care. CMAJ. 2007;177(12): 1513-9.

109. Holm LV, Hansen DG, Larsen PV, Johansen C, Vedsted P, Bergholdt $\mathrm{SH}$, et al. Social inequality in cancer rehabilitation: a population-based cohort study. Acta Oncol. 2013;52(2):410-22.

110. Addis ME, Mahalik JR. Men, masculinity, and the contexts of help seeking. Am Psychol. 2003;58(1):5-14.

111. Handberg C, Lomborg K, Nielsen CV, Oliffe JL, Midtgaard J. Understanding male cancer patients' barriers to participating in cancer rehabilitation. Eur J Cancer Care (Engl). 2015;24(6):80111.

112. Cecil R, Mc Caughan E, Parahoo K. 'It's hard to take because I am a man's man': an ethnographic exploration of cancer and masculinity. Eur J Cancer Care (Engl). 2010;19(4):501-9.

113. Garrouste-Orgeas M, Montuclard L, Timsit JF, Reignier J, Desmettre T, Karoubi P, et al. Predictors of intensive care unit refusal in French intensive care units: a multiple-center study. Crit Care Med. 2005;33(4):750-5.

114. Romo H, Amaral AC, Vincent JL. Effect of patient sex on intensive care unit survival. Arch Intern Med. 2004;164(1):61-5.

115. Raine R, Goldfrad C, Rowan K, Black N. Influence of patient gender on admission to intensive care. J Epidemiol Community Health. 2002;56(6):418-23.

116. The L. GLOBOCAN 2018: counting the toll of cancer. Lancet. 2018:392(10152):985.

117. Booij JC, Zegers M, Evers PM, Hendriks M, Delnoij DM, Rademakers JJ. Improving cancer patient care: development of a generic cancer consumer quality index questionnaire for cancer patients. BMC Cancer. 2013;13:203.

118. Hopman P, Gijsen B, Brink M, Rijken M. Zorg- en leefsituatie van mensen met kanker 2012. Deelrapportage I: Ervaringen met ziekenhuiszorg.: NIVEL;2012. https://nivel.nl/sites/default/files/ bestanden/DeelrapportI-Ervaringen-met-ziekenhuiszorg.pdf. Accessed 16 March 2020.

119. Stewart BW, Wild CP. World Cancer Report 2014. Lyon, france. 2014. http://publications.iarc.fr/ publications/media/download/ 5839/bc44643f904185d5c8eddb933480b5bc18b21dba.pdf. Accessed 16 March 2020.

120. Factsheet all cancer 2018. world health organization;2018. http:// gco.iarc.fr/today/data/factsheets/cancers/39-All-cancers-factsheet.pdf. Accessed 16 March 2020.

121. Courneya KSVJ, Gill S, et al. Update on the colon health and lifelong exercise change trial: a phase III study of the impact of an exercise program on disease-free survival in colon cancer survivors. Curr Colorectal Cancer Rep. 2014;10:321-8.

122. Eyl RE, Xie K, Koch-Gallenkamp L, Brenner H, Arndt V. Quality of life and physical activity in long-term $(>/=5$ years post-diagnosis) colorectal cancer survivors - systematic review. Health Qual Life Outcomes. 2018;16(1):112.

123. Des Guetz G, Uzzan B, Bouillet T, et al. Impact of physical activity on cancer-specific and overall survival of patients with colorectal cancer. Gastroenterol Res Pract. 2013;2013:340851.

124. Je Y, Jeon JY, Giovannucci EL, Meyerhardt JA. Association between physical activity and mortality in colorectal cancer: a metaanalysis of prospective cohort studies. Int J Cancer. 2013;133(8): 1905-13.

125. Goode AD, Lawler SP, Brakenridge CL, Reeves MM, Eakin EG. Telephone, print, and web-based interventions for physical activity, diet, and weight control among cancer survivors: a systematic review. J Cancer Surviv. 2015;9(4):660-82.

126. Bluethmann SM, Vernon SW, Gabriel KP, Murphy CC, Bartholomew LK. Taking the next step: a systematic review and meta-analysis of physical activity and behavior change interventions in recent post-treatment breast cancer survivors. Breast Cancer Res Treat. 2015;149(2):331-42. 
127. Courneya KS, Vardy JL, O'Callaghan CJ, Friedenreich CM, Campbell KL, Prapavessis H, et al. Effects of a structured exercise program on physical activity and fitness in colon cancer survivors: one year feasibility results from the CHALLENGE trial. Cancer Epidemiol Biomark Prev. 2016;25(6):969-77.

128. Short CE, Rebar A, James EL, Duncan MJ, Courneya KS, Plotnikoff RC, et al. How do different delivery schedules of tailored web-based physical activity advice for breast cancer survivors influence intervention use and efficacy? J Cancer Surviv. 2017;11(1):80-91.

129. Kanera IM, Willems RA, Bolman CA, Mesters I, Verboon P, Lechner L. Long-term effects of a web-based cancer aftercare intervention on moderate physical activity and vegetable consumption among early cancer survivors: a randomized controlled trial. Int J Behav Nutr Phys Act. 2017;14(1):19.

130. Kuijpers W, Groen WG. Development of MijnAVL, an interactive portal to empower breast and lung cancer survivors: an iterative, multi-stakeholder approach. JMIR Res Protoc. 2015;4(1):e14.

131. Kuijpers W, Groen WG. eHealth for breast cancer survivors: use, feasibility and impact of an interactive portal. JMIR Cancer. 2016;2(1):e3.

132. Timmerman JG, Dekker-van Weering MGH, Stuiver MM, et al. Ambulant monitoring and web-accessible home-based exercise program during outpatient follow-up for resected lung cancer survivors: actual use and feasibility in clinical practice. J Cancer Surviv. 2017;11(6):720-31.

133. Rutten IJ, van Dijk DP, Kruitwagen RF, Beets-Tan RG, Olde Damink SW, van Gorp T. Loss of skeletal muscle during neoadjuvant chemotherapy is related to decreased survival in ovarian cancer patients. J Cachexia Sarcopenia Muscle. 2016;7(4):45866.

134. Prado CM, Lieffers JR, McCargar LJ, et al. Prevalence and clinical implications of sarcopenic obesity in patients with solid tumours of the respiratory and gastrointestinal tracts: a population-based study. Lancet Oncol. 2008;9(7):629-35.

135. Costa LJ, Varella PC, del Giglio A. Weight changes during chemotherapy for breast cancer. Sao Paulo Med J. 2002;120(4): 113-7.

136. Ferioli M, Zauli G, Martelli AM, et al. Impact of physical exercise in cancer survivors during and after antineoplastic treatments. Oncotarget. 2018;9(17):14005-34.

137. Grande AJ, Silva V, Maddocks M. Exercise for cancer cachexia in adults: executive summary of a Cochrane collaboration systematic review. J Cachexia Sarcopenia Muscle. 2015;6(3):208-11.
138. Crawford JJ, Holt NL, Vallance JK, Courneya KS. A new paradigm for examining the correlates of aerobic, strength, and combined exercise: an application to gynecologic cancer survivors. Support Care Cancer. 2016;24(8):3533-41.

139. Courneya KS, Segal RJ, Reid RD, Jones LW, Malone SC, Venner $\mathrm{PM}$, et al. Three independent factors predicted adherence in a randomized controlled trial of resistance exercise training among prostate cancer survivors. J Clin Epidemiol. 2004;57(6):571-9.

140. Boslooper K, Kibbelaar R, Storm H, Veeger NJGM, Hovenga S, Woolthuis G, et al. Treatment with rituximab, cyclophosphamide, doxorubicin, vincristine and prednisolone is beneficial but toxic in very elderly patients with diffuse large B-cell lymphoma: a population-based cohort study on treatment, toxicity and outcome. Leuk Lymphoma. 2014;55(3):526-32.

141. van de Schans SA, Wymenga AN, van Spronsen DJ, Schouten HC, Coebergh JW, Janssen-Heijnen ML. Two sides of the medallion: poor treatment tolerance but better survival by standard chemotherapy in elderly patients with advanced-stage diffuse large Bcell lymphoma. Ann Oncol. 2012;23(5):1280-6.

142. Lin TL, Kuo MC, Shih LY, Dunn P, Wang PN, Wu JH, et al. The impact of age, Charlson comorbidity index, and performance status on treatment of elderly patients with diffuse large B cell lymphoma. Ann Hematol. 2012;91(9):1383-91.

143. Narayanan V, Koshy C. Fatigue in cancer: a review of literature. Indian J Palliat Care. 2009;15(1):19-25.

144. Juvet LK, Thune I, Elvsaas IKO, Fors EA, Lundgren S, Bertheussen G, et al. The effect of exercise on fatigue and physical functioning in breast cancer patients during and after treatment and at 6 months follow-up: a meta-analysis. Breast. 2017;33:166-77.

145. Olsson Möller U, Olsson I-M, Sjövall K, Beck I, Rydén L, Malmström M. Barriers and facilitators for individualized rehabilitation during breast cancer treatment - a focus group study exploring health care professionals' experiences. BMC Health Serv Res. 2020;20(1):252.

146. Smith-Turchyn J, Richardson J, Tozer R, McNeely M, Thabane L. Physical activity and breast cancer: a qualitative study on the barriers to and facilitators of exercise promotion from the perspective of health care professionals. (0300-0508 (Print)).

Publisher's note Springer Nature remains neutral with regard to jurisdictional claims in published maps and institutional affiliations. 